\title{
Beyond breast and ovarian cancers: PARP inhibitors for BRCA mutation-associated and BRCA-like solid tumors
}

\section{Ciara C. O'Sullivan' ${ }^{1}$, Dominic H. Moon ${ }^{1,2}$, Elise C. Kohn' ${ }^{1}$ and Jung-Min Lee ${ }^{1 *}$}

' Medical Oncology Branch, Center for Cancer Research, National Cancer Institute, Bethesda, MD, USA

${ }^{2}$ Medical Research Scholars Program, National Institutes of Health, Bethesda, MD, USA

\section{Edited by:}

Kristin Zorn, Magee-Womens

Hospital of UPMC, USA

Reviewed by:

Silvia Soddu, Regina Elena Cancer Institute, Italy

Lin Liu, Nankai University, China

*Correspondence:

Jung-Min Lee, Medical Oncology Branch, Center for Cancer Research, National Cancer Institute, 10 Center Dr. MSC 1906, Building 10, Room 12N/226, Bethesda, MD 20892, USA e-mail: leej6@mail.nih.gov
Poly(ADP-ribose) polymerase inhibitors (PARPi) have shown clinical activity in patients with germline BRCA1/2 mutation (gBRCAm)-associated breast and ovarian cancers. Accumulating evidence suggests that PARPi may have a wider application in the treatment of cancers defective in DNA damage repair pathways, such as prostate, lung, endometrial, and pancreatic cancers. Several PARPi are currently in phase I/II clinical investigation, as single-agents and/or combination therapy in these solid tumors. Understanding more about the molecular abnormalities involved in BRCA-like phenotype in solid tumors beyond breast and ovarian cancers, exploring novel therapeutic trial strategies and drug combinations, and defining potential predictive biomarkers are critical to expanding the scope of PARPi therapy. This will improve clinical outcome in advanced solid tumors. Here, we briefly review the preclinical data and clinical development of PARPi, and discuss its future development in solid tumors beyond gBRCAm-associated breast and ovarian cancers.

Keywords: poly(ADP-ribose) polymerase inhibitors, solid tumors, BRCA mutation, BRCA-like, DNA damage repair pathway

\section{INTRODUCTION}

Increasing understanding of the cellular aberrations inherent to cancer cells has allowed the development of therapies targeting biological pathways. This approach has been an important step toward individualization of therapy for germline BRCA1/2 mutation $(\mathrm{gBRCAm})$-associated breast and ovarian cancers $(1,2)$. The clinical development of poly(ADP-ribose) polymerase inhibitors (PARPi), with their selective mechanisms of action involving the DNA damage repair pathways, is an example of this strategy. Early clinical trials have shown significant single-agent activity of PARPi in gBRCAm-associated breast and ovarian cancers (3-5). Response rates (RR) of $31-40 \%$ have been reported in gBRCAm ovarian cancer patients with measureable recurrent disease, and the RR and duration of response to PARPi monotherapy has been associated with platinum sensitivity $(6,7)$. Emerging evidence suggests that PARPi is an effective therapeutic strategy in subsets of other malignancies that have gBRCAm, such as melanoma, prostate, and pancreatic cancers. BRCA-like tumors have molecular and clinical characteristics in common with tumors occurring in patients with gBRCAm, which may have implications for PARPi-based therapy (8). Additionally, there is a potential therapeutic role for PARP inhibition in a wider subgroup of solid tumors that may have defective homologous recombination (HR) (9). Therefore, the utility of PARPi in other solid tumors is potentially greater than was previously envisioned (8).

PARPi have shown to enhance cytotoxicity in combination with DNA methylating agents $(10,11)$, topoisomerase inhibitors $(12,13)$, platinums $(14,15)$, alkylating agents $(14)$, and radiation $(16,17)$ in numerous preclinical studies. These preclinical findings are being explored in clinical trials to elucidate the role of PARPi as chemo- and radiosensitizers in various tumor types (18). A large number of clinical trials are exploring the efficacy of combination strategies in malignancies such as non-small cell lung cancer (NSCLC), squamous cell cancer of the head and neck (HNSCC), esophageal, and colorectal cancers (CRCs) (Tables 1 and 2); the results of several phase I and II trials have already been reported (Table 3). These data suggest further clinical exploration of PARPi as monotherapy or combinations is warranted in patients not only with gBRCAmassociated breast or ovarian cancer, but also in solid tumors with HR dysfunction.

gBRCAm-associated and BRCA-like tumors are rare subsets of advanced solid tumors. Approximately $5-10 \%$ of breast (27) and $10-15 \%$ of ovarian cancers (28) occur in the setting of a hereditary cancer syndrome, the most common of which is a gBRCAm (29). This occurs less frequently in other solid tumors. Approximately $5 \%$ of cutaneous melanoma and gastric cancers are related to gBRCAm and $5-19 \%$ cases of familial pancreatic cancer are attributed to a gBRCAm $(30,31)$. Furthermore, gBRCAm are very rare events in patients with prostate cancer and NSCLC. gBRCAm are present in $0.44-1.2 \%$ of prostate cancer cases $(32,33)$. The overall incidence of gBRCAm in patients with NSCLC has not been reported from large trials; only 3 patients $(2.7 \%)$ were noted to have a gBRCAm in a study of 110 Jewish men with epithelial growth factor receptor (EGFR) mutant-NSCLC (34). These subgroups of tumors with germline HR dysfunction constitute a rare population with recognized unmet therapeutic needs, and may be sensitive to treatment with PARPi. Additionally, there are significant unanswered questions of their use in solid tumors that have molecular and clinical characteristics in common with gBRCAmassociated tumors. Advances have been made in identifying new therapeutic targets and analyzing response to novel treatments 
Table 1 | PARPi in clinical development (excluding breast and ovarian cancer) (19)

\begin{tabular}{|c|c|c|c|}
\hline Name & Treatment & Cancer types & Phase \\
\hline \multirow[t]{4}{*}{ Olaparib (AstraZeneca) } & Monotherapy & GBM, prostate, ES, NSCLC, CRC, and gastric cancer & $|/| \mid$ \\
\hline & Combination with chemotherapy & Esophageal cancer and HNSCC & \\
\hline & Combination with RT & & \\
\hline & Combination with targeted therapies & & \\
\hline Rucaparib (Clovis) & Combination with chemotherapy & AST & 1 \\
\hline \multirow[t]{4}{*}{ Veliparib (Abbott) } & Monotherapy & gBRCAm prostate cancer, HNSCC, NSCLC, SCLC, pancreatic & $|/| \mid$ \\
\hline & Combination with chemotherapy & cancer, biliary cancers, HCC, rectal cancer, cervical cancer, CRPC, & \\
\hline & Combination with RT & and CNS malignancies & \\
\hline & Combination with targeted therapies & & \\
\hline \multirow[t]{2}{*}{ CEP-9722 (Cephalon) } & Monotherapy & AST & I \\
\hline & Combination with chemotherapy & & \\
\hline E7016 (EISAI) & Combination with chemotherapy & Melanoma and AST & $|/| \mid$ \\
\hline BMN-673 (BioMarin) & Monotherapy & AST & 1 \\
\hline
\end{tabular}

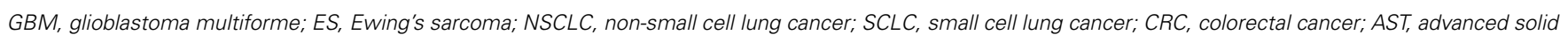

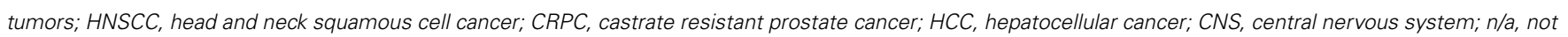
applicable.

in these patient subgroups and this has led to an explosion of PARPi-based clinical trials extending the patient cohort to include BRCA-like tumors.

\section{PARP FUNCTION AND INHIBITION IN DNA DAMAGE REPAIR PATHWAYS}

DNA damage can occur through various mechanisms from environmental factors such as ultraviolet rays, ionizing radiation, and genotoxic chemicals, to endogenous processes including generation of reactive oxygen species and replication (35). Highly complex and intertwined repair pathways have evolved to provide broad and redundant mechanisms to address damaged DNA: mismatch repair (MMR), base excision repair (BER), and nucleotide excision repair (NER) for a low fidelity single strand DNA break (SSB) repair mechanism, and HR and non-homologous endjoining (NHEJ) for double-strand DNA breaks (DSBs) (36). The different repair mechanisms are orchestrated by numerous enzymes to ensure the integrity of DNA essential for cell survival.

PARP are a family of enzymes that catalyze nicotinamide adenine dinucleotide $\left(\mathrm{NAD}^{+}\right)$-dependent ADP-ribosylation of DNA. PARP1 is the best characterized member of the PARP family, and PARP2 has a similar structure and function with varying affinity for substrates (37). PARP1 has been implicated in several DNA repair mechanisms including the repair of SSBs through the BER pathway. It recognizes and binds to DNA sites with SSB via its DNA binding domain, then subsequently synthesizes poly(ADP-ribose) (PAR) by transferring ADP-ribose molecules from $\mathrm{NAD}^{+}$to itself and other acceptor proteins (38). This activates the formation of a DNA repair complex consisting of multiple repair proteins, including DNA ligase III and X-ray repair cross-complementing 1 (XRCC1) (39). The PARylated PARP1 dissociates from DNA as the negative charge of PAR decreases its affinity for DNA, and poly(ADP-ribose) glycohydrolase then degrades the PAR on PARP1 (40). PARP has been shown to have a direct involvement in DSB repair in addition to its role in preventing DSB formation by promoting BER. In PARP1-deficient cells, ATM-kinase function is compromised leading to a reduction in DNA DSB in response to radiation, indicating a role of PARP1 in ATM activation and HR $(38,41)$. PARP1 has been shown to reduce DSB formation by sensing stalled replication forks and recruiting MRE11 for end processing to initiate HR (42). Increased PARP1 expression and/or activity in tumor cells have been demonstrated in many tumor types $(43,44)$. Thus, HR dysfunction sensitizes cells to PARP inhibition leading to further chromosomal instability, cell cycle arrest, and apoptosis $(45,46)$.

PARPi are a class of drugs designed to compete with $\mathrm{NAD}^{+}$ for the substrate binding site of PARP, acting as an effective catalytic inhibitor (47). PARP inhibition has been shown to induce phosphorylation of DNA-dependent protein kinase (DNA$\mathrm{Pk}$ ), to further stimulate error-prone NHEJ in HR-deficient cells (44, 48, 49). More recently, another mechanism of action of PARPi involving PARP1-trapping has been proposed (50). PARPi have been shown to trap PARP1 and PARP2 while in complex with damaged DNA, resulting in cytotoxic consequences (51). Trapped PARP prevents its availability for repair function and secondarily causes replication and transcription fork blockade, and subsequent DNA breakage. This mechanism of action may be important to the clinical activity of the PARPi class. The potency in trapping PARP differs markedly among PARPi, with niraparib (MK-4827) and olaparib having greater potency than veliparib. This pattern is not correlated with the catalytic inhibitory properties of each drug. These findings suggest that PARPi have several mechanisms of action and multiple targets in the DNA repair pathway to potentially induce cancer cell death (Figure 1). 
Table 2 | Trials of PARPi in solid tumors (excluding breast and ovarian cancers).

\begin{tabular}{|c|c|c|c|}
\hline Malignancy & PARPi & Combination agent(s) & Phase \\
\hline Pancreatic & $\begin{array}{l}\text { Olaparib } \\
\text { Veliparib }\end{array}$ & $\begin{array}{l}\text { Chemotherapy } \\
\text { Cisplatin } \\
\text { Gemcitabine } \\
\text { Gemcitabine/IMRT } \\
\text { Monotherapy (gBRCAm pancreatic cancer) } \\
\text { Modified FOLFOX } 6\end{array}$ & $1 / 11$ \\
\hline Pancreatic, biliary, urothelial and NSCLC & Veliparib & Cisplatin and gemcitabine & I \\
\hline Liver & Veliparib & Cisplatin and gemcitabine & I \\
\hline Colorectal cancer & $\begin{array}{l}\text { Veliparib } \\
\text { Olaparib } \\
\text { Veliparib }\end{array}$ & $\begin{array}{l}\text { TMZ } \\
\text { Irinotecan } \\
\text { Capecitabine and RT }\end{array}$ & $1 / I 1$ \\
\hline Esophageal cancer & Olaparib & RT & I \\
\hline Gastric cancer & $\begin{array}{l}\text { Veliparib } \\
\text { Olaparib }\end{array}$ & $\begin{array}{l}\text { FOLFIRI } \\
\text { Paclitaxel }\end{array}$ & $1 / I 1$ \\
\hline \multicolumn{4}{|l|}{ LUNG } \\
\hline NSCLC (surgically unresectable) & $\begin{array}{l}\text { Olaparib } \\
\text { Veliparib }\end{array}$ & $\begin{array}{l}\text { Concurrent RT } \pm \text { cisplatin } \\
\text { RT } \\
\text { Carboplatin/paclitaxel } \\
\text { Cisplatin/gemcitabine }\end{array}$ & $1 / I 1$ \\
\hline EGFR mutation positive advanced NSCLC & Olaparib & Gefitinib \pm olaparib & $1 / I 1$ \\
\hline Cervical cancer & Veliparib & $\begin{array}{l}\text { Cisplatin and paclitaxel } \\
\text { Topotecan } \\
\text { Carboplatin and paclitaxel }\end{array}$ & $|/| \mid$ \\
\hline Uterine carcinosarcoma & Veliparib & Carboplatin and paclitaxel & II \\
\hline \multicolumn{4}{|l|}{ CENTRAL NERVOUS SYSTEM } \\
\hline GBM & $\begin{array}{l}\text { Olaparib } \\
\text { Veliparib }\end{array}$ & $\begin{array}{l}\text { TMZ } \\
\text { TMZ }\end{array}$ & $\begin{array}{l}1 \\
1 / I 1\end{array}$ \\
\hline Brain metastases & Veliparib & WBRT & $1 / I 1$ \\
\hline DPG & Veliparib & $\begin{array}{l}\text { RT } \\
\text { TMZ }\end{array}$ & $1 / I 1$ \\
\hline Refractory CNS tumors & Veliparib & TMZ & I \\
\hline HEAD AND NECK & & & \\
\hline HNSCC & Veliparib & $\begin{array}{l}\text { RT } \\
\text { Docetaxel } \\
\text { 5-FU }\end{array}$ & $|/| \mid$ \\
\hline
\end{tabular}


Table 2 | Continued

\begin{tabular}{|c|c|c|c|}
\hline Malignancy & PARPi & Combination agent(s) & Phase \\
\hline \multicolumn{4}{|l|}{ SARCOMA } \\
\hline Ewing's sarcoma & Olaparib & $\mathrm{N} / \mathrm{A}$ & II \\
\hline \multicolumn{4}{|l|}{ SKIN CANCER } \\
\hline \multirow[t]{2}{*}{ Melanoma } & Veliparib & TMZ & II \\
\hline & E7016 & TMZ & \\
\hline \multicolumn{4}{|c|}{ ADVANCED SOLID TUMORS } \\
\hline & \multirow[t]{6}{*}{ Veliparib } & Carboplatin and gemcitabine & $|/| \mid$ \\
\hline & & Gemcitabine & \\
\hline & & Carboplatin and paclitaxel & \\
\hline & & Mitomycin C & \\
\hline & & Capecitabine and oxaliplatin & \\
\hline & & Cyclophosphamide & \\
\hline & \multirow[t]{3}{*}{ Olaparib } & Cisplatin/gemcitabine & \\
\hline & & PLD & \\
\hline & & Topotecan & \\
\hline & Niraparib & Monotherapy & \\
\hline & CEP-9722 & Monotherapy & \\
\hline & BMN-673 & Monotherapy & \\
\hline
\end{tabular}

IMRT, intensity modulated radiotherapy; NSCLC, non-small cell lung cancer; RT, radiotherapy; MSI, microsatellite instability; CRPC, castrate resistant prostate cancer; SCLC, small cell lung cancer; GBM, glioblastoma multiforme; DPG, diffuse pontine glioma; HNSCC, squamous cell carcinoma of the head and neck; 5-FU, 5-fluorouracil; $P L D$, pegylated liposomal doxorubicin.

\section{PARP INHIBITION IN gBRCAm AND BRCA-LIKE SOLID TUMORS}

Understanding DNA repair biology has allowed the identification of patient subsets with high potential for response to PARPi treatment. The marked susceptibility of patients with gBRCAm has validated gBRCAm as a predictive biomarker for PARPi response in breast and ovarian cancer patients. In a series of pivotal preclinical studies, PARPi were noted to cause selective cytotoxicity for in vitro and in vivo models of BRCA-deficient cells $(52,53)$. Additionally, PARPi attenuates tumor formation in embryonic stem cell-derived teratocarcinoma xenograft models (46). These findings were translated into a phase I clinical trial of the PARPi, olaparib, in recurrent breast, ovarian, and prostate cancer patients with gBRCAm (4), initiating a new era of possibilities for the use of PARPi as single-agent therapy to treat gBRCAm-associated cancers.

The BRCA-like behavior has been described based on clinical and molecular features that parallel gBRCAm-associated cancers' characteristics. The major clinical BRCA-like behavior identified is susceptibility to platinums and other DNA-damaging agents (54-56). Some of the molecular events described in BRCA-like behavior include epigenetic silencing of BRCA1 through promoter methylation (57-59) and overexpression of EMSY, suppressing BRCA2 transcription (60). In addition, loss or disruption of proteins necessary for HR such as RAD51, ATM, ATR, CHK1, CHK2, FANCD2, and FANCA $(53,61-64)$ are observed in a variety of tumors $(8,65-71)$, and may confer sensitivity to PARPi $(8,53)$. Defects in translesion synthesis (TLS) also contribute to carcinogenesis but confer sensitivity to DNA-damaging agents $(72,73)$, requiring further investigation on sensitivity to PARPi.
Homozygous mutation in the PTEN tumor suppressor gene may also lead to HR dysfunction (74). Increased PARPi sensitivity was shown in a series of cell lines with PTEN mutation or haploinsufficiency, and confirmed in xenograft models using olaparib (74). There is also clinical evidence that olaparib may have a therapeutic utility in PTEN-deficient endometrial cancer $(75,76)$. Further studies are needed to investigate whether PTEN loss can serve as a potential biomarker for PARPi sensitivity (77-79). Future studies should focus on DNA profiling and the use of predictive biomarkers to select those tumors which are more likely to respond to PARPi. Ongoing research suggests HR deficiency, rather than a specific mutation in the BRCA genes, may be the main driver of cytotoxicity of PARP inhibition (45).

\section{TRIALS WITH PARPi IN gBRCAm AND/OR BRCA-LIKE ADVANCED SOLID TUMORS MALIGNANT MELANOMA}

Little is known about the underlying cause of hereditary cancer predisposition in melanoma and its impact on the prognosis and therapeutic decisions. Cutaneous melanoma has been associated with mutations in the BRCA2 gene although there are only a few cases reported for uveal melanoma in BRCA2 mutation carriers (80). In recent years, the advent of BRAF V600E inhibitors (e.g., vemurafenib) and anti-CTLA4 antibodies (e.g., ipilimumab) has significantly improved outcomes in patients with metastatic melanoma (81-83), with a median duration of response of 8 and 16 months, respectively $(84,85)$. However, most patients eventually progress and some do not tolerate therapy due to immune-related side effects, indicating the need to develop other therapeutic strategies. 


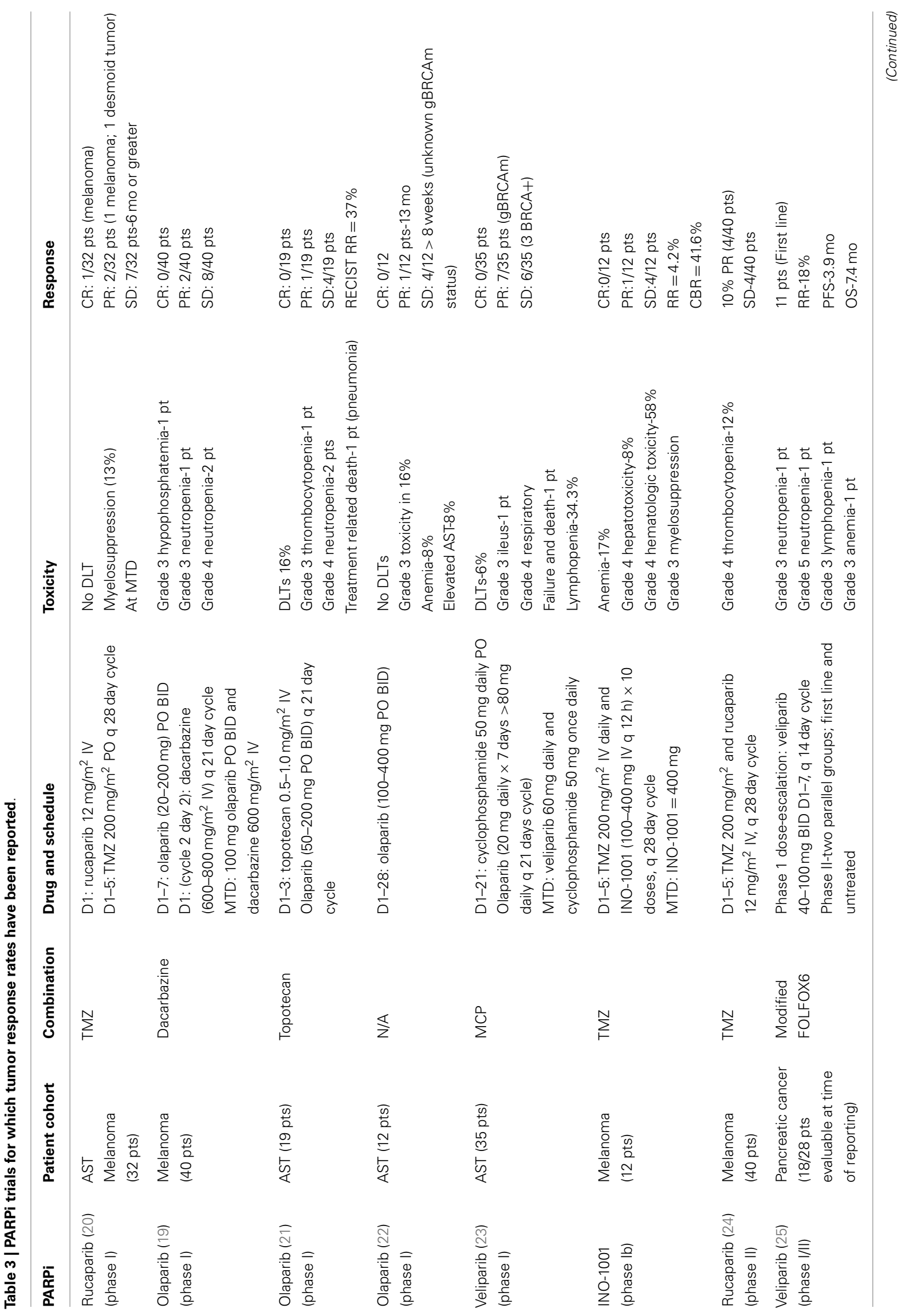




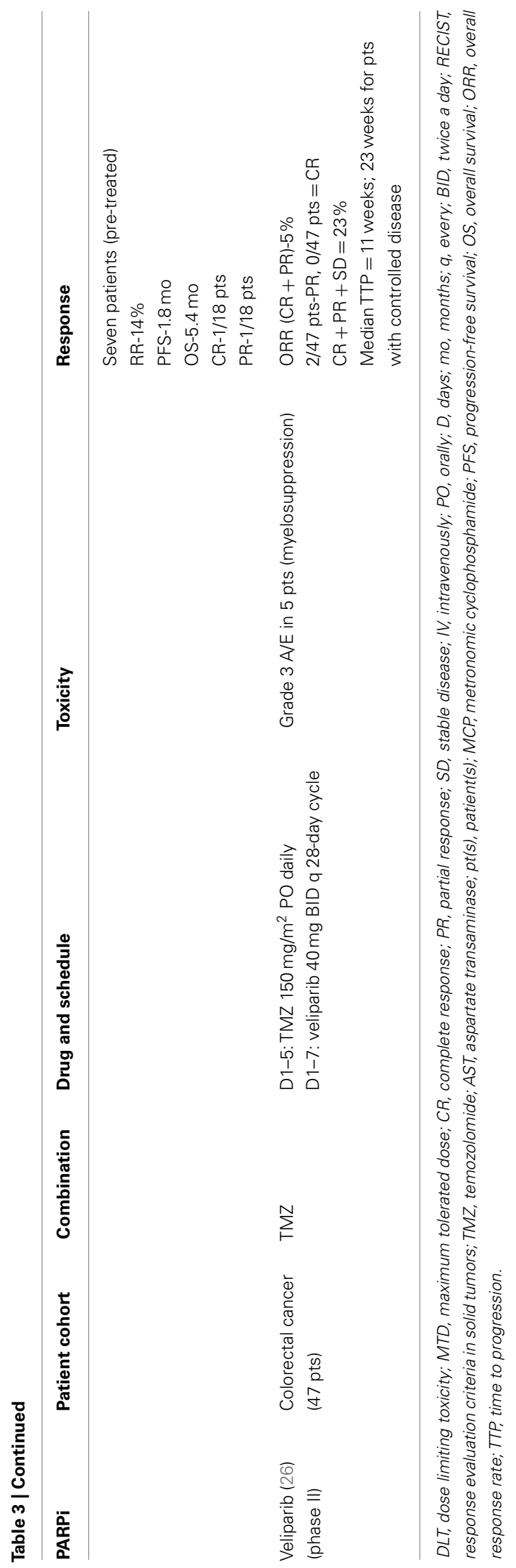

PARPi have multiple targets in DNA repair pathways that can potentially promote cancer cell death. In the setting of melanoma, altered expression or new mutations in DNA MMR genes, MLH1 and MSH2, have been reported in brain metastases (86). A melanoma cell line (MZ7), derived from a patient who received dacarbazine therapy, exhibited a high level of resistance to temozolomide (TMZ) without expressing $O(6)$-methylguanineDNA methyltransferase (MGMT), which was related to impaired expression of MSH2 and MSH6 (87). PARP inhibition with INO1001 has been shown to restore sensitivity to TMZ in an MMRdeficient xenograft model of malignant melanoma (88), and another PARPi, GPI 15427, enhanced TMZ anti-tumor activity in various cancers, including metastatic melanoma in an orthotopic xenograft mouse model (24). These preclinical studies provide evidence that MMR loss of function is a potential predictive biomarker of PARPi responsiveness in patients with metastatic melanoma.

A number of clinical trials of PARPi in melanoma patients have been conducted or are ongoing although they have not specifically addressed the frequency of HR dysfunction/gBRCAm in their populations. Bedikian et al. reported the results of a phase IB study of intravenous INO-1001 and oral TMZ in unselected patients with unresectable stage III or IV melanoma (89). The dose limiting toxicities (DLTs) were elevation of liver transaminases and myelosuppression at the 400-mg dose of INO-1001. Of the 12 patients enrolled, 1 patient had a partial response (PR) and 4 patients had stable disease (SD). Several phase II studies using PARPi either as a single-agent or in combination with chemotherapy, radiotherapy, or targeted therapy are summarized in Table 3. A phase II trial sought to evaluate the combination of rucaparib and TMZ in patients with metastatic malignant melanoma (90). The disease-control rate was $40 \%(8 / 20)$, where four patients attained a PR and four others had prolonged SD. In total, 12 of the 40 patients required a dose reduction of TMZ secondary to myelosuppression (90). Another phase II study evaluated treatment with rucaparib $12 \mathrm{mg} / \mathrm{m}^{2}$ and TMZ $200 \mathrm{mg} / \mathrm{m}^{2}$ in patients with advanced melanoma. Myelosuppression was again noted, with 25 patients (54\%) requiring a $25 \%$ dose reduction in TMZ. The RR was $17.4 \%$, with median time to progression and OS of 3.5 and 9.9 months, respectively. This study demonstrated that TMZ could safely be given with a PARP-inhibitory dose (PID) of rucaparib $\left(12 \mathrm{mg} / \mathrm{m}^{2}\right)$, based on $74-97 \%$ inhibition in PARP of peripheral blood mononuclear cells (PBMCs). This resulted in an increase in PFS compared with historical controls (91). Phase I and II trials evaluating E7016 in combination with TMZ in patients with advanced solid tumors and malignant melanoma are ongoing $(92,93)$. Eligibility criteria for the phase II study include BRAF wild-type status and no prior treatment with TMZ or PARPi. As substantial progress has been made in the management of malignant melanoma in recent years (94), it remains to be seen whether PARPi will be added to the treatment armamentarium.

\section{PANCREATIC CANCER}

Hereditary pancreatic cancer is rare and extremely heterogeneous, and it accounts for approximately $2 \%$ of all pancreatic cancer cases. The major component of hereditary pancreatic cancer is the familial pancreatic cancer syndrome. Although up to $20 \%$ of 


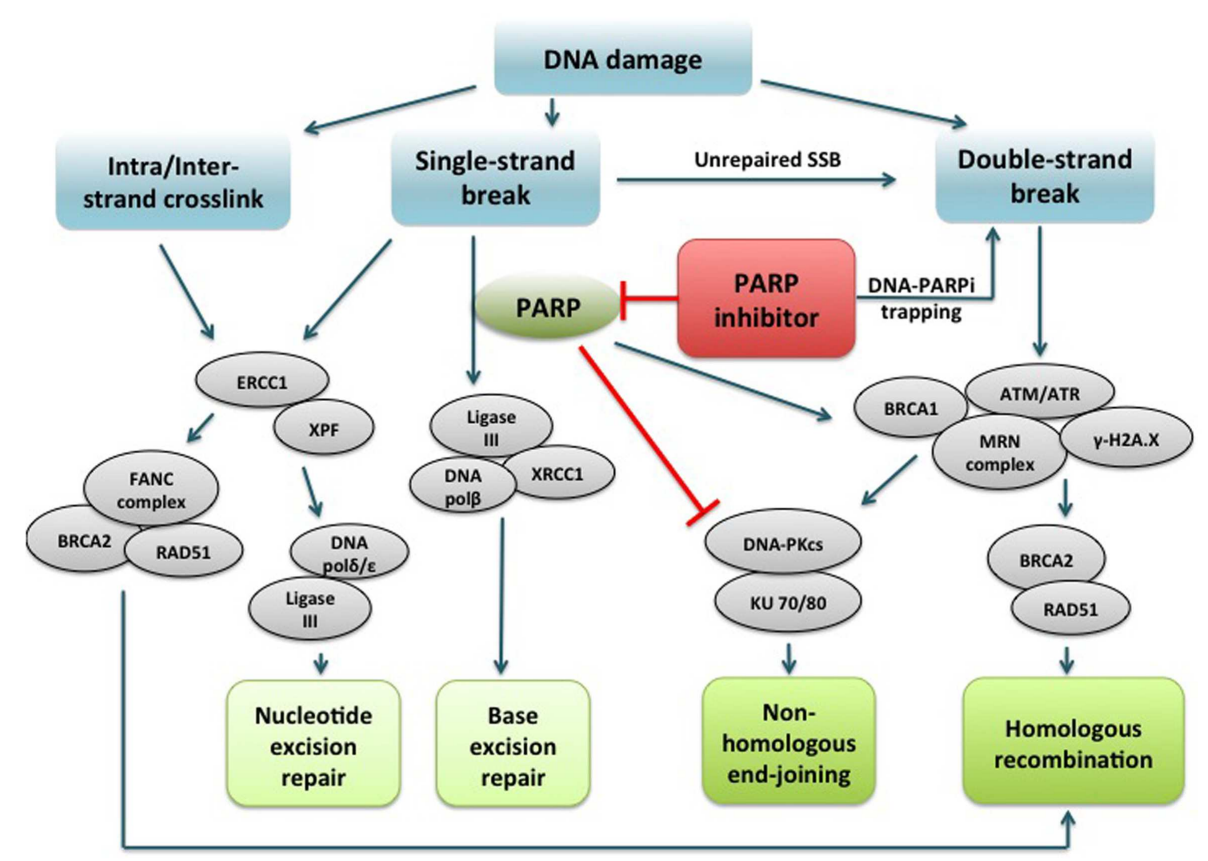

FIGURE 1 | PARP1 binds to DNA single strand break and catalyzes poly(ADP-ribosyl)ation of itself and acceptor proteins, which facilitates recruitment of DNA repair proteins. In addition to its reported role in base excision repair, PARP1 plays a role in activating ATM necessary for homologous recombination and inactivating DNA-dependent protein kinase, a key component of non-homologous end-joining. PARP inhibitors directly interfere with the above functions of PARP1. In addition, PARP inhibitors have been shown to trap PARP1 on damaged DNA, leading to replication and transcription fork blockage and subsequent double-strand DNA breakage. Repair of intra/interstrand crosslinks through nucleotide excision repair or homologous recombination are also important components of the DNA repair system, and whether defects in these repair pathways can confer sensitivity to PARPi are under investigation. PARP, poly(ADP-ribose) polymerase; PARPi, PARP inhibitor; DNA pol $\beta / \delta / \varepsilon$, DNA polymerase beta/delta/epsilon; XRCC1, X-ray repair

cross-complementing protein 1; DNA-PKcs, DNA-dependent protein kinase catalytic subunit; KU 70/80, a.k.a XRCC6/5 (X-ray repair

cross-complementing protein 6/5); ATM, ataxia telangiectasia mutated; ATR, ataxia telangiectasia and Rad3-related; $\gamma$-H2A.X, gamma-histone $\mathrm{H} 2 \mathrm{~A}$ member X; RAD51, RAD51 homolog (S. cerevisiae); ERCC1, DNA excision repair protein ERCC1; XPF, DNA repair endonclease XPF (xeroderma pigmentosum group F-complementing protein); FANC, Fanconi anemia. hereditary pancreatic cancer cases are associated with germline mutations in BRCA2, CDKN2A, PRSS1, STKI1, or MMR genes, the major underlying gene defects are still unknown (95). BRCA2 mutation prevalence in familial pancreatic cancer patients varies between 5 and 19\% (30), and a BRCA2 mutation increases the risk of developing pancreatic cancer by approximately 3.5 -fold (96). The unique biology of cancer cells with BRCA mutations offers potential therapeutic advantages with agents such as platinums. However, one case series report patients with gBRCAm did not reveal a benefit to first line platinum chemotherapy in the treatment of advanced pancreatic cancer (97), although this needs to be further evaluated in a selected study for pancreatic cancer with gBRCAm. Preclinical studies have shown single-agent activity of PARPi (98), as well as radiosensitization in combination with chemoradiation in BRCA2-deficient pancreatic cells (25). Studies are ongoing to examine single-agent and combination PARPi therapy in BRCA2 mutant pancreatic cancers.

Interim results from an ongoing phase II study of olaparib monotherapy in gBRCAm-associated advanced solid cancers were recently reported (99). Nearly $8 \%$ of the patients $(23 / 298)$ had advanced/recurrent pancreatic cancer. A RR of 5/23 (21.7\%) was noted, with eight patients achieving SD. This yielded a clinical benefit rate of $57 \%$ in gBRCAm-associated pancreatic cancer patients.
Pishvaian et al. reported a phase I study of veliparib with concurrent FOLFOX chemotherapy in patients with metastatic pancreatic cancer (100). Twenty-eight patients were enrolled in the trial and at the time of review, data were available for 18 patients. For the 11 patients who were treated in the first line setting, RR was $18 \%$, with a PFS and OS of 3.9 and 7.4 months, respectively (Table 3). Therefore, the investigators concluded that the experimental combination regimen could be given safely, and was modestly active (100). These data support further evaluation of PARPi either as different combinations or more potent PARPi with chemotherapy and/or other targeted agents combination in this subgroup of pancreatic cancer patients.

\section{PROSTATE CANCER}

Germline BRCA2 mutation confers the highest genetic risk of prostate cancer known to date at 8.6 -fold in men $\leq 65$ years, whereas the effect of BRCA1 is more modest at 3.4-fold $(32,33$, $101,102)$. Prostate cancer in patients with gBRCAm tends to be more aggressive, with a higher likelihood of nodal involvement and distant metastasis with inferior survival outcomes (103). Trials analyzing the response of these patients to DNA-damaging agents, such as platinums, and identifying the therapeutic targets of this subgroup are urgently needed. 
Single-agent olaparib has demonstrated activity in patients with gBRCAm castration resistant prostate cancer (CRPC). A phase I olaparib study by Fong et al. reports one gBRCA2m patient treated with single-agent olaparib who sustained a CR lasting in excess of 2 years (4). Recently, Sandhu et al. presented clinical data on four patients with advanced gBRCAm CRPC, three of whom were treated with olaparib and one with niraparib (104). Two patients on olaparib showed prostate-specific antigen (PSA) and radiologic responses lasting 26 and 34 months, respectively, while the third patient had SD for 10 months. The patient on niraparib exhibited primary resistance with development of a new liver lesion and a rise in PSA of nearly threefold at the time of the first reassessment. Translational studies revealed positive ERG staining by immunohistochemistry, and ERG rearrangements by FISH, as well as either heterozygous or homozygous PTEN allelic loss in all four cases. Subsets of patients with CRPC are also known to manifest increased PARP activity (105). This potentially opens another avenue for therapy utilizing PARPi, although gBRCAm is a very rare event in prostate cancer.

Gene fusion between the ERG proto-oncogene and TMPRSS2 promoter is a major genomic alteration observed in approximately $50 \%$ of prostate cancers. Formation of the TMPRSS2-ERG fusion gene causes aberrant androgen-dependent ERG expression (106) and promotes tumorigenesis (107). Preclinical studies have shown that PARP1 directly interacts with ERG to inhibit ETS gene fusion protein activity. In turn, inhibition of PARP1 reduces ETS-positive, but not ETS-negative, prostate cancer xenograft growth (108). This may be a useful predictive biomarker for PARPi sensitivity.

Other preclinical studies include radiosensitization by rucaparib, most evident in PTEN-deficient prostate cancer cells containing the TMPRSS2-ERG fusion gene (109). However, no association was noted between loss of PTEN expression by immunohistochemistry and ETS rearrangements by FISH, with radiologic assessment of the anti-tumor activity of niraparib in 18 patients with prostate cancer (110). The HR/PARP synthetic lethality model may be more widely applicable in prostate cancer with germline or somatic inactivating mutations in the HR DNA repair genes, CHK2, BRIPI/FANCJ, NBS1, BRCA1, and ATM, collectively thought to occur in $20-25 \%$ of prostate cancer cases. Recently, a phase II study of olaparib in unselected patients with CRPC was initiated (111).

Veliparib has also been investigated and shown to enhance the anti-tumor activity of TMZ in prostate cancer xenografts, yielding tumor size reduction in TMZ-resistant PC3-Leu prostate cancer mice (112). This formed the rationale for testing the efficacy and safety of veliparib and TMZ in 26 patients with metastatic CRPC (113). Grade III/IV thrombocytopenia was noted in 15\% of patients. Two patients had a confirmed PSA response and four patients had SD for at least 4 months. The median PFS and OS were 2.1 (95\% CI: 1.8, 3.9) and 9.1 (95\% CI: 5.5, 11.7) months, respectively. This study suggested veliparib and TMZ are tolerated well, but with limited clinical activity. Future trials will explore the use of different chemotherapy agents in combination with higher doses of veliparib. Overall, further evaluation of biochemical changes or predictive biomarkers in response to PARPi in advanced prostate cancer is needed.

\section{COLON CANCER}

Preclinical data suggest the utility of PARPi in tumors deficient in $\mathrm{HR}$ and displaying microsatellite instability (MSI) due to mutations in the coding microsatellites of the MRE11A and hRAD50 genes involved in DNA DSB repair (114). Preferential cytotoxicity to the PARP1 inhibitor ABT-888 was seen in MSI cell lines containing mutant copies of MRE11A, compared with wild-type or microsatellite stable (MSS) cells (115). In a recent study, the observed ability of MSH3 to protect against DSB was exploited by the combination of oxaliplatin and a PARPi, which produced a synergistic cytotoxic effect against CRC cells (116). Another study reporting high correlation between MRE11 mutations and MSI in CRC cell lines as well as primary tumors, found that PARPi preferentially kills MSI cell lines harboring MRE11 mutations (115). The data suggest a role for PARPi in MSI-CRC treatment, providing a rationale for clinical studies in this subset of patients.

Dozens of potential PARPi have been screened in vitro and in vivo to select candidates for clinical evaluation as a chemosensitizer in CRC (117). A phase II trial is currently evaluating the efficacy of olaparib in metastatic CRC (mCRC) stratified for MSI status (118). Twenty-two patients with MSI-negative tumors were enrolled and received a mean number of two cycles. Preliminary data indicate no single-agent activity of olaparib against nonMSI-high (MSI-H) mCRC. Accrual of MSI-H mCRC patients continues, along with active biomarker analysis. Other clinical trials of PARPi in MSI-CRC are in progress.

Studies have evaluated and validated veliparib as a sensitizer to irinotecan, oxaliplatin, and radiation therapy (RT) in CRC cells $(26,119)$. Several phase II studies are evaluating the role of PARPi as a chemosensitizer in patients with advanced and mCRC, irrespective of MSI status (Table 2). Pishvaian et al. (120) conducted a single arm, open label phase II study in patients with unresectable or mCRC. Patients were treated with TMZ $\left(150 \mathrm{mg} / \mathrm{m}^{2}\right.$ orally daily) days $1-5$, and veliparib ( $40 \mathrm{mg}$ orally twice a day) days 1-7 of each 28-day cycle. Immunohistochemistry was performed on archived tumor samples to quantify MMR and PTEN protein expression. The combination of veliparib and TMZ was well tolerated in the 47 patients treated, with a disease-control rate of $23 \%$. The results of immunohistochemistry for the MMR and PTEN proteins from 45 archived tumor samples are not yet reported. It was concluded that, in a heavily pre-treated population of patients with $\mathrm{MCRC}$, the combination of veliparib and TMZ can be safely given, and displayed limited clinical activity.

\section{LUNG CANCER}

Reduced BRCA1 mRNA and protein expression levels have been observed in up to $44 \%$ of NSCLC, occurring through various mechanisms such as promoter hypermethylation (121). One study showed that BRCA1 silencing increased susceptibility to olaparib treatment in NSCLC cell lines (122), providing evidence for possible clinical application in this subset of NSCLCs. A future study will assess the utility of olaparib in delaying the time to disease progression in patients with advanced NSCLC who have responded to initial chemotherapy (123). The role of PTEN mutation and its effect on the susceptibility to PARPi is an area of continued research in lung and other malignancies. Up to $9 \%$ of NSCLCs 
have a somatic mutation in PTEN. Olaparib has yielded additive activity with cisplatin in homozygous deleted PTEN-deficient NSCLC cells and xenograft models (79). Another gene involved in DNA repair, excision repair cross-complementation group 1 (ERCC1), is a key component of NER and the main mechanism for removing platinum-DNA adducts (124). Preclinical studies have explored this repair pathway, demonstrating synergy of olaparib and veliparib with cisplatin in NSCLC cell lines with low ERCC1 expression levels $(125,126)$. PARPi have also been explored preclinically in combination with other DNA-damaging modalities such as RT (16).

The role of PARPi in patients with EGFR mutant NSCLC has been studied in a phase IB study of olaparib and the EGFR tyrosine kinase inhibitor (TKI) gefitinib (127). It was noted that high BRCA1 mRNA expression is associated with a shorter PFS in EGFR-mutated patients treated with erlotinib. To date, 18 patients have received treatment at four different dose levels of olaparib ranging 100-200 mg twice daily dose, and 200-250 mg three times daily dose. DLT was grade 3 anemia observed at dose level 4 (250 $\mathrm{mg}$ three times daily). Of the 17 patients in whom a disease response could be evaluated, $7(41.1 \%)$ had a PR. All of the patients who responded were EGFR TKI naive. Another seven patients (41.1\%), most of whom received prior treatment, had documented $\mathrm{SD}$, and three patients (17.6\%), all of whom had prior EGFR TKI treatment, progressed. The observed anti-tumor activity will be further evaluated in EGFR TKI treatment-naive patients with EGFR-mutated NSCLC; a phase II randomized trial comparing the efficacy of olaparib and gefitinib versus gefitinib alone was launched in July 2013.

Multiple studies are also exploring the role of PARPi in combination with chemotherapy and/or RT in NSCLC. A phase I dose-escalation trial of olaparib and concurrent RT, with or without cisplatin, is ongoing in patients with advanced NSCLC (128). SWOG 1206, a phase I/II trial, is evaluating the use of veliparib with or without RT and carboplatin/paclitaxel in patients with inoperable stage III NSCLC. Several similar studies involving other combinations of PARPi \pm chemotherapy and/or RT are ongoing in patients with NSCLC (Table 2). Ultimately, combining PARPi with cisplatin or radiotherapy may prove to be a useful strategy in the treatment of NSCLC.

\section{EWING'S SARCOMA}

PARPi has preclinically shown anti-tumor activity in the treatment of Ewing's sarcoma. Gene fusions involving Ewing's sarcoma breakpoint region 1 (EWS) and ETS transcription factors have been implicated in abnormal proliferation, invasion, and tumorigenesis (129). PARP inhibition has been evaluated as an effective treatment option for Ewing's sarcoma with EWS-FLI1 or EWSERG genomic fusions in xenograft models (130), and olaparib has been shown to have potent activity in cell lines with a EWS/FLI1 translocation (131). Additionally, a study in preclinical models showed synergy between PARPi and TMZ (130) in the treatment of Ewing's sarcoma cell lines. Currently, a number of clinical trials investigating the utility of PARPi in Ewing's sarcoma are underway $(132,133)$.

\section{CHALLENGES AND FUTURE DIRECTIONS FOR CLINICAL DEVELOPMENT IN CANCERS OTHER THAN BREAST AND OVARIAN}

There is considerable interest in the clinical development of PARPi for use in solid tumors other than breast and ovarian cancers. The optimal dose, scheduling, and sequencing of PARPi, and combination with other cytotoxic or biologic agents need to be evaluated in carefully designed clinical trials. The incorporation of predictive biomarkers into studies of gBRCAm and BRCA-like cancers presents challenges. First is the development of a mechanism with which to identify patients who are most likely to benefit from PARPi therapy. Predictive biomarkers applied to readily available bioresources, such as archival tissue or non-tumor tissue, have been proposed. Changes in or baseline PAR incorporation into PBMC DNA was suggested and evaluated as a putative early ontreatment pharmacodynamic measure; while present, there was no relationship to clinical outcome (134). BRCA1/2 somatic mutation or promoter methylation, ATM mutation, MRE11-dominant negative mutations in MMR-deficient cancers, FANCF promotor methylation and PTEN deficiency are all potential biomarkers of sensitivity to PARPi (51). Importantly, not all patients with deficiencies in BRCA1 or 2 are responsive to PARP inhibition (135). Therefore, identification and validation of predictive biomarkers of those gBRCAm who will respond to PARPi is also an important area of ongoing research.

The second challenge is dissecting and defining mechanisms of development of resistance to PARPi, and whether they portend potential collateral resistance to other DNA-damaging agents. Acquisition of a secondary mutation in BRCA1/2 that allows BRCA1/2 gene read-through and yields a functional protein has been demonstrated in cell lines and some patients; this was correlated with loss of susceptibility to PARPi treatment (136). Other potential mechanisms of clinical resistance have been proposed based on preclinical models, including loss of 53BP1, or increased activity of RAD51 (137, 138). Whether these findings can be used as selective or predictive biomarker is yet to be determined. Ang et al. recently reported that gBRCAm-associated ovarian cancer patients retain the potential to respond to subsequent chemotherapy, including platinum-based agents, after progression on PARPi (139). This observation has implications for chemotherapy sequencing. Further studies are needed to evaluate outcomes to subsequent chemotherapies or another PARPi in other solid tumor patients who have a BRCA-like phenotype. Understanding the mechanism(s) of resistance to PARPi will lead to optimal application and sequencing of PARPi and other DNA-damaging agents.

\section{CONCLUSION}

PARPi are a class of agents with mechanisms of action beyond their documented role in BER pathway. They potentially have a broader application in the treatment of cancer patients, both within the confines of gBRCAm and BRCA-like disease, but also extending to a wide range of aberrations in DNA damage repair pathways. Ongoing research will aim to identify optimal predictive biomarkers in order to improve patient selection and thus, clinical responses to treatment. It is anticipated that novel clinical trial 
design strategies will help minimize toxicity and maximize therapeutic efficacy. Other pertinent questions relate to the duration of treatment and long-term effects of treatment, which need to be carefully investigated (20). Future directions for PARPi will include clinical trials directed at patient subsets that are most likely to respond to treatment, based on their molecular characteristics and predictive biomarkers. This may ultimately result in practice-changing treatments in malignancies such as pancreatic cancer, prostate cancer, and Ewing's sarcoma. The results of trials of PARPi, either as single-agents or in combination with chemotherapy, RT, or biological agents in other solid tumors are eagerly awaited.

\section{AUTHOR CONTRIBUTIONS}

All authors substantially contributed to the concept of the manuscript, drafted and revised, and approved final version.

\section{ACKNOWLEDGMENTS}

This work was supported by the Intramural Program of the Center for Cancer Research, National Cancer Institute. Dominic H. Moon was funded through the NIH Medical Research Scholars Program, a public-private partnership supported jointly by the $\mathrm{NIH}$ and through the Foundation for the NIH (details on program and donors: http://www.fnih.org/work/programs-development/ medical-research-scholars-program).

\section{REFERENCES}

1. Rosen EM, Fan S, Pestell RG, Goldberg ID. BRCA1 gene in breast cancer. J Cell Physiol (2003) 196(1):19-41. doi:10.1002/jcp.10257

2. Tavtigian SV, Simard J, Rommens J, Couch F, Shattuck-Eidens D, Neuhausen $\mathrm{S}$, et al. The complete BRCA2 gene and mutations in chromosome 13q-linked kindreds. Nat Genet (1996) 12(3):333-7. doi:10.1038/ng0396-333

3. Audeh MW, Carmichael J, Penson RT, Friedlander M, Powell B, Bell-McGuinn $\mathrm{KM}$, et al. Oral poly(ADP-ribose) polymerase inhibitor olaparib in patients with BRCA1 or BRCA2 mutations and recurrent ovarian cancer: a proof-ofconcept trial. Lancet (2010) 376(9737):245-51. doi:10.1016/S0140-6736(10) 60893-8

4. Fong PC, Boss DS, Yap TA, Tutt A, Wu P, Mergui-Roelvink M, et al. Inhibition of poly(ADP-ribose) polymerase in tumors from BRCA mutation carriers. $N$ Engl J Med (2009) 361(2):123-34. doi:10.1056/NEJMoa0900212

5. Tutt A, Robson M, Garber JE, Domchek SM, Audeh MW, Weitzel JN, et al. Oral poly(ADP-ribose) polymerase inhibitor olaparib in patients with BRCA1 or BRCA2 mutations and advanced breast cancer: a proof-of-concept trial. Lancet (2010) 376(9737):235-44. doi:10.1016/S0140-6736(10)60892-6

6. Fong PC, Yap TA, Boss DS, Carden CP, Mergui-Roelvink M, Gourley C, et al. Poly(ADP)-ribose polymerase inhibition: frequent durable responses in BRCA carrier ovarian cancer correlating with platinum-free interval. J Clin Oncol (2010) 28(15):2512-9. doi:10.1200/JCO.2009.26.9589

7. Kaye SB, Lubinski J, Matulonis U, Ang JE, Gourley C, Karlan BY, et al. Phase II, open-label, randomized, multicenter study comparing the efficacy and safety of olaparib, a poly (ADP-ribose) polymerase inhibitor, and pegylated liposomal doxorubicin in patients with BRCA1 or BRCA2 mutations and recurrent ovarian cancer. J Clin Oncol (2012) 30(4):372-9. doi:10.1200/JCO.2011.36. 9215

8. Turner N, Tutt A, Ashworth A. Hallmarks of 'BRCAness' in sporadic cancers. Nat Rev Cancer (2004) 4(10):814-9. doi:10.1038/nrc1457

9. Yap TA, Sandhu SK, Carden CP, de Bono JS. Poly(ADP-ribose) polymerase (PARP) inhibitors: exploiting a synthetic lethal strategy in the clinic. CA Cancer J Clin (2011) 61(1):31-49. doi:10.3322/caac.20095

10. Curtin NJ, Wang LZ, Yiakouvaki A, Kyle S, Arris CA, Canan-Koch S, et al. Novel poly(ADP-ribose) polymerase-1 inhibitor, AG14361, restores sensitivity to temozolomide in mismatch repair-deficient cells. Clin Cancer Res (2004) 10(3):881-9. doi:10.1158/1078-0432.CCR-1144-3
11. Liu X, Shi Y, Guan R, Donawho C, Luo Y, Palma J, et al. Potentiation of temozolomide cytotoxicity by poly(ADP)ribose polymerase inhibitor ABT- 888 requires a conversion of single-stranded DNA damages to doublestranded DNA breaks. Mol Cancer Res (2008) 6(10):1621-9. doi:10.1158/15417786

12. Delaney CA, Wang LZ, Kyle S, White AW, Calvert AH, Curtin NJ, et al. Potentiation of temozolomide and topotecan growth inhibition and cytotoxicity by novel poly(adenosine diphosphoribose) polymerase inhibitors in a panel of human tumor cell lines. Clin Cancer Res (2000) 6(7):2860-7.

13. Smith LM, Willmore E, Austin CA, Curtin NJ. The novel poly(ADP-ribose) polymerase inhibitor, AG14361, sensitizes cells to topoisomerase I poisons by increasing the persistence of DNA strand breaks. Clin Cancer Res (2005) 11(23):8449-57. doi:10.1158/1078-0432.CCR-05-1224

14. Donawho CK, Luo Y, Penning TD, Bauch JL, Bouska JJ, Bontcheva-Diaz VD, et al. ABT-888, an orally active poly(ADP-ribose) polymerase inhibitor that potentiates DNA-damaging agents in preclinical tumor models. Clin Cancer Res (2007) 13(9):2728-37. doi:10.1158/1078-0432.CCR-06-3039

15. Miknyoczki SJ, Jones-Bolin S, Pritchard S, Hunter K, Zhao H, Wan W, et al. Chemopotentiation of temozolomide, irinotecan, and cisplatin activity by CEP-6800, a poly(ADP-ribose) polymerase inhibitor. Mol Cancer Ther (2003) 2(4):371-82.

16. Albert JM, Cao C, Kim KW, Willey CD, Geng L, Xiao D, et al. Inhibition of poly(ADP-ribose) polymerase enhances cell death and improves tumor growth delay in irradiated lung cancer models. Clin Cancer Res (2007) 13(10):3033-42. doi:10.1158/1078-0432.CCR-06-2872

17. Chalmers A, Johnston P, Woodcock M, Joiner M, Marples B. PARP-1, PARP-2, and the cellular response to low doses of ionizing radiation. Int J Radiat Oncol Biol Phys (2004) 58(2):410-9. doi:10.1016/j.ijrobp.2003.09.053

18. Underhill C, Toulmonde M, Bonnefoi H. A review of PARP inhibitors: from bench to bedside. Ann Oncol (2011) 22(2):268-79. doi:10.1093/annonc/ mdq322

19. Davar D, Beumer JH, Hamieh L, Tawbi H. Role of PARP inhibitors in cancer biology and therapy. Curr Med Chem (2012) 19(23):3907-21. doi:10.2174/ 092986712802002464

20. Weil MK, Chen AP. PARP inhibitor treatment in ovarian and breast cancer. Curr Probl Cancer (2011) 35(1):7-50. doi:10.1016/j.currproblcancer.2010.12.002

21. Plummer R, Middleton M, Wilson R, Jones C, Evans J, Robson L, et al. First in human phase I trial of the PARP inhibitor AG-014699 with temozolomide (TMZ) in patients (pts) with advanced solid tumors. J Clin Oncol (2005) 23(Suppl 16):abstr3065.

22. Khan OA, Gore M, Lorigan P, Stone J, Greystoke A, Burke W, et al. A phase I study of the safety and tolerability of olaparib (AZD2281, KU0059436) and dacarbazine in patients with advanced solid tumours. Br J Cancer (2011) 104(5):750-5. doi:10.1038/bjc.2011.422

23. Samol J, Ranson M, Scott E, Macpherson E, Carmichael J, Thomas A, et al. Safety and tolerability of the poly(ADP-ribose) polymerase (PARP) inhibitor, olaparib (AZD2281) in combination with topotecan for the treatment of patients with advanced solid tumors: a phase I study. Invest New Drugs (2012) 30(4):1493-500. doi:10.1007/s10637-011-9682-9

24. Tentori L, Leonetti C, Scarsella M, D’Amati G, Vergati M, Portarena I, et al. Systemic administration of GPI 15427, a novel poly(ADP-ribose) polymerase-1 inhibitor, increases the antitumor activity of temozolomide against intracranial melanoma, glioma, lymphoma. Clin Cancer Res (2003) 9(14):5370-9.

25. Porcelli L, Quatrale AE, Mantuano P, Leo MG, Silvestris N, Rolland JF, et al. Optimize radiochemotherapy in pancreatic cancer: PARP inhibitors a new therapeutic opportunity. Mol Oncol (2012) 7(3):308-22. doi:10.1016/j.molonc. 2012.10.002

26. Davidson D, Wang Y, Aloyz R, Panasci L. The PARP inhibitor ABT-888 synergizes irinotecan treatment of colon cancer cell lines. Invest New Drugs (2013) 31(2):461-8. doi:10.1007/s10637-012-9886-7

27. Hemel D, Domchek SM. Breast cancer predisposition syndromes. Hematol Oncol Clin North Am (2010) 24(5):799-814. doi:10.1016/j.hoc.2010.06.004

28. Russo A, Calo V, Bruno L, Rizzo S, Bazan V, Di Fede G. Hereditary ovarian cancer. Crit Rev Oncol Hematol (2009) 69(1):28-44. doi:10.1016/j.critrevonc. 2008.06.003

29. Kobayashi H, Ohno S, Sasaki Y, Matsuura M. Hereditary breast and ovarian cancer susceptibility genes (review). Oncol Rep (2013) 30(3):1019-29. doi:10.3892/or.2013.2541 
30. Lucas AL, Shakya R, Lipsyc MD, Mitchel EB, Kumar S, Hwang C, et al. High prevalence of BRCA1 and BRCA2 germline mutations with loss of heterozygosity in a series of resected pancreatic adenocarcinoma and other neoplastic lesions. Clin Cancer Res (2013) 19(13):3396-403. doi:10.1158/10780432

31. Brose MS, Rebbeck TR, Calzone KA, Stopfer JE, Nathanson KL, Weber BL. Cancer risk estimates for BRCA1 mutation carriers identified in a risk evaluation program. J Natl Cancer Inst (2002) 94(18):1365-72. doi:10.1093/jnci/94. 18.1365

32. Kote-Jarai Z, Leongamornlert D, Saunders E, Tymrakiewicz M, Castro E, Mahmud N, et al. BRCA2 is a moderate penetrance gene contributing to young-onset prostate cancer: implications for genetic testing in prostate cancer patients. Br J Cancer (2011) 105(8):1230-4. doi:10.1038/bjc.2011.383

33. Leongamornlert D, Mahmud N, Tymrakiewicz M, Saunders E, Dadaev T, Castro E, et al. Germline BRCA1 mutations increase prostate cancer risk. Br J Cancer (2012) 106(10):1697-701. doi:10.1038/bjc.2012.146

34. Marks JL, Golas B, Kirchoff T, Miller VA, Riely GJ, Offit K, et al. EGFR mutant lung adenocarcinomas in patients with germline BRCA mutations. J Thorac Oncol (2008) 3(7):805. doi:10.1097/JTO.0b013e31817e4664

35. Hoeijmakers JH. Genome maintenance mechanisms for preventing cancer. Nature (2001) 411(6835):366-74. doi:10.1038/35077232

36. Bernstein C, Bernstein H, Payne CM, Garewal H. DNA repair/pro-apoptotic dual-role proteins in five major DNA repair pathways: fail-safe protection against carcinogenesis. Mutat Res (2002) 511(2):145-78. doi:10.1016/S13835742(02)00009-1

37. Ame JC, Rolli V, Schreiber V, Niedergang C, Apiou F, Decker P, et al. PARP-2, a novel mammalian DNA damage-dependent poly(ADP-ribose) polymerase. J Biol Chem (1999) 274(25):17860-8. doi:10.1074/jbc.274.25.17860

38. Haince JF, Kozlov S, Dawson VL, Dawson TM, Hendzel MJ, Lavin MF, et al. Ataxia telangiectasia mutated (ATM) signaling network is modulated by a novel poly(ADP-ribose)-dependent pathway in the early response to DNA-damaging agents. J Biol Chem (2007) 282(22):16441-53. doi:10.1074/jbc.M608406200

39. Masson M, Niedergang C, Schreiber V, Muller S, Menissier-de Murcia J, de Murcia G. XRCC1 is specifically associated with poly(ADP-ribose) polymerase and negatively regulates its activity following DNA damage. Mol Cell Biol (1998) 18(6):3563-71.

40. Heitz F, Harter P, Ewald-Riegler N, Papsdorf M, Kommoss S, du Bois A. Poly(ADP-ribosyl)ation polymerases: mechanism and new target of anticancer therapy. Expert Rev Anticancer Ther (2010) 10(7):1125-36. doi:10.1586/ era. 10.53

41. Aguilar-Quesada R, Munoz-Gamez JA, Martin-Oliva D, Peralta A, Valenzuela MT, Matinez-Romero R, et al. Interaction between ATM and PARP-1 in response to DNA damage and sensitization of ATM deficient cells through PARP inhibition. BMC Mol Biol (2007) 8:29. doi:10.1186/1471-2199-8-29

42. Bryant HE, Petermann E, Schultz N, Jemth AS, Loseva O, Issaeva N, et al. PARP is activated at stalled forks to mediate Mre11-dependent replication restart and recombination. EMBO J (2009) 28(17):2601-15. doi:10.1038/ emboj.2009.206

43. D’Amours D, Desnoyers S, D’Silva I, Poirier GG. Poly(ADP-ribosyl)ation reactions in the regulation of nuclear functions. Biochem J (1999) 342(Pt 2):249-68. doi:10.1042/0264-6021:3420249

44. Patel AG, Sarkaria JN, Kaufmann SH. Nonhomologous end joining drives poly(ADP-ribose) polymerase (PARP) inhibitor lethality in homologous recombination-deficient cells. Proc Natl Acad Sci U S A (2011) 108(8):3406-11. doi:10.1073/pnas.1013715108

45. Ashworth A. A synthetic lethal therapeutic approach: poly(ADP) ribose polymerase inhibitors for the treatment of cancers deficient in DNA double-strand break repair. J Clin Oncol (2008) 26(22):3785-90. doi:10.1200/JCO.2008.16. 0812

46. Farmer H, McCabe N, Lord CJ, Tutt AN, Johnson DA, Richardson TB, et al Targeting the DNA repair defect in BRCA mutant cells as a therapeutic strategy. Nature (2005) 434(7035):917-21. doi:10.1038/nature03445

47. Rouleau M, Patel A, Hendzel MJ, Kaufmann SH, Poirier GG. PARP inhibition: PARP1 and beyond. Nat Rev Cancer (2010) 10(4):293-301. doi:10.1038/ $\operatorname{nrc} 2812$

48. Mansour WY, Rhein T, Dahm-Daphi J. The alternative end-joining pathway for repair of DNA double-strand breaks requires PARP1 but is not dependent upon microhomologies. Nucleic Acids Res (2010) 38(18):6065-77. doi:10.1093/nar/gkq387
49. Wang M, Wu W, Rosidi B, Zhang L, Wang H, Iliakis G. PARP-1 and Ku compete for repair of DNA double strand breaks by distinct NHEJ pathways. Nucleic Acids Res (2006) 34(21):6170-82. doi:10.1093/nar/gkl840

50. Helleday T. The underlying mechanism for the PARP and BRCA synthetic lethality: clearing up the misunderstandings. Mol Oncol (2011) 5(4):387-93. doi:10.1016/j.molonc.2011.07.001

51. Murai J, Huang SY, Das BB, Renaud A, Zhang Y, Doroshow JH, et al. Trapping of PARP1 and PARP2 by clinical PARP inhibitors. Cancer Res (2012) 72(21):5588-99. doi:10.1158/0008-5472

52. Bryant HE, Schultz N, Thomas HD, Parker KM, Flower D, Lopez E, et al. Specific killing of BRCA2-deficient tumours with inhibitors of poly(ADP-ribose) polymerase. Nature (2005) 434(7035):913-7. doi:10.1038/nature03443

53. McCabe N, Turner NC, Lord CJ, Kluzek K, Bialkowska A, Swift S, et al. Deficiency in the repair of DNA damage by homologous recombination and sensitivity to poly(ADP-ribose) polymerase inhibition. Cancer Res (2006) 66(16):8109-15. doi:10.1158/0008-5472.CAN-06-0140

54. Gallagher DJ, Konner JA, Bell-McGuinn KM, Bhatia J, Sabbatini P, Aghajanian CA, et al. Survival in epithelial ovarian cancer: a multivariate analysis incorporating BRCA mutation status and platinum sensitivity. Ann Oncol (2011) 22(5):1127-32. doi:10.1093/annonc/mdq577

55. Safra T, Borgato L, Nicoletto MO, Rolnitzky L, Pelles-Avraham S, Geva R, et al. BRCA mutation status and determinant of outcome in women with recurrent epithelial ovarian cancer treated with pegylated liposomal doxorubicin. $\mathrm{Mol}$ Cancer Ther (2011) 10(10):2000-7. doi:10.1158/1535-7163.MCT-11-0272

56. Alsop K, Fereday S, Meldrum C, deFazio A, Emmanuel C, George J, et al. BRCA mutation frequency and patterns of treatment response in BRCA mutationpositive women with ovarian cancer: a report from the Australian Ovarian Cancer Study Group. J Clin Oncol (2012) 30(21):2654-63. doi:10.1200/JCO. 2011.39.8545

57. Birgisdottir V, Stefansson OA, Bodvarsdottir SK, Hilmarsdottir H, Jonasson JG, Eyfjord JE. Epigenetic silencing and deletion of the BRCA1 gene in sporadic breast cancer. Breast Cancer Res (2006) 8(4):R38. doi:10.1186/bcr1522

58. Esteller M, Silva JM, Dominguez G, Bonilla F, Matias-Guiu X, Lerma E, et al. Promoter hypermethylation and BRCAl inactivation in sporadic breast and ovarian tumors. J Natl Cancer Inst (2000) 92(7):564-9. doi:10.1093/jnci/ 92.7.564

59. Wei M, Grushko TA, Dignam J, Hagos F, Nanda R, Sveen L, et al. BRCA1 promoter methylation in sporadic breast cancer is associated with reduced BRCA1 copy number and chromosome 17 aneusomy. Cancer Res (2005) 65(23):10692-9. doi:10.1158/0008-5472.CAN-05-1277

60. Hughes-Davies L, Huntsman D, Ruas M, Fuks F, Bye J, Chin SF, et al. EMSY links the BRCA2 pathway to sporadic breast and ovarian cancer. Cell (2003) 115(5):523-35. doi:10.1016/S0092-8674(03)00930-9

61. Long KC, Kauff ND. Hereditary ovarian cancer: recent molecular insights and their impact on screening strategies. Curr Opin Oncol (2011) 23(5):526-30. doi:10.1097/CCO.0b013e3283499da9

62. Walsh T, Casadei S, Lee MK, Pennil CC, Nord AS, Thornton AM, et al. Mutations in 12 genes for inherited ovarian, fallopian tube, and peritoneal carcinoma identified by massively parallel sequencing. Proc Natl Acad Sci U S A (2011) 108(44):18032-7. doi:10.1073/pnas.1115052108

63. Cancer Genome Atlas Research Network. Integrated genomic analyses of ovarian carcinoma. Nature (2011) 474(7353):609-15. doi:10.1038/nature10166

64. Konstantinopoulos PA, Spentzos D, Karlan BY, Taniguchi T, Fountzilas E, Francoeur N, et al. Gene expression profile of BRCAness that correlates with responsiveness to chemotherapy and with outcome in patients with epithelial ovarian cancer. J Clin Oncol (2010) 28(22):3555-61. doi:10.1200/JCO.2009.27.5719

65. Bullrich F, Rasio D, Kitada S, Starostik P, Kipps T, Keating M, et al. ATM mutations in B-cell chronic lymphocytic leukemia. Cancer Res (1999) 59(1):24-7.

66. Couch FJ, Johnson MR, Rabe K, Boardman L, McWilliams R, de Andrade M, et al. Germ line Fanconi anemia complementation group $\mathrm{C}$ mutations and pancreatic cancer. Cancer Res (2005) 65(2):383-6.

67. Vorechovsky I, Luo L, Ortmann E, Steinmann D, Dork T. Missense mutations at ATM gene and cancer risk. Lancet (1999) 353(9160):1276. doi:10.1016/S01406736(05)75199-0

68. Bell DW, Varley JM, Szydlo TE, Kang DH, Wahrer DC, Shannon KE, et al. Heterozygous germ line hCHK2 mutations in Li-Fraumeni syndrome. Science (1999) 286(5449):2528-31. doi:10.1126/science.286.5449.2528

69. Miller CW, Ikezoe T, Krug U, Hofmann WK, Tavor S, Vegesna V, et al. Mutations of the CHK2 gene are found in some osteosarcomas, but are rare in breast, 
lung, and ovarian tumors. Genes Chromosomes Cancer (2002) 33(1):17-21. doi:10.1002/gcc. 1207

70. Marsit CJ, Liu M, Nelson HH, Posner M, Suzuki M, Kelsey KT. Inactivation of the Fanconi anemia/BRCA pathway in lung and oral cancers: implications for treatment and survival. Oncogene (2004) 23(4):1000-4. doi:10.1038/sj.onc. 1207256

71. Narayan G, Arias-Pulido H, Nandula SV, Basso K, Sugirtharaj DD, Vargas $\mathrm{H}$, et al. Promoter hypermethylation of FANCF: disruption of Fanconi Anemia-BRCA pathway in cervical cancer. Cancer Res (2004) 64(9):2994-7. doi:10.1158/0008-5472.CAN-04-0245

72. Makridakis NM, Reichardt JK. Translational DNA polymerases and cancer. Front Genet (2012) 3:174. doi:10.3389/fgene.2012.00174.ecollection 2012

73. Curtin NJ. DNA repair dysregulation from cancer driver to therapeutic target. Nat Rev Cancer (2012) 12(12):801-17. doi:10.1038/nrc3399

74. Mendes-Pereira AM, Martin SA, Brough R, McCarthy A, Taylor JR, Kim JS, et al. Synthetic lethal targeting of PTEN mutant cells with PARP inhibitors. EMBO Mol Med (2009) 1(6-7):315-22. doi:10.1002/emmm.200900041

75. Dedes KJ, Wetterskog D, Mendes-Pereira AM, Natrajan R, Lambros MB, Geyer FC, et al. PTEN deficiency in endometrioid endometrial adenocarcinomas predicts sensitivity to PARP inhibitors. Sci Transl Med (2010) 2:53ra75. doi:10.1126/scitranslmed.3001538

76. Forster MD, Dedes KJ, Sandhu S, Frentzas S, Kristeleit R, Ashworth A, et al. Treatment with olaparib in a patient with PTEN-deficient endometrioid endometrial cancer. Nat Rev Clin Oncol (2011) 8(5):302-6. doi:10.1038/ nrclinonc. 2011.42

77. Fraser M, Zhao H, Luoto KR, Lundin C, Coackley C, Chan N, et al. PTEN deletion in prostate cancer cells does not associate with loss of RAD51 function: implications for radiotherapy and chemotherapy. Clin Cancer Res (2012) 18(4):1015-27. doi:10.1158/1078-0432.CCR-11-2189

78. Hunt CR, Gupta A, Horikoshi N, Pandita TK. Does PTEN loss impair DNA double-strand break repair by homologous recombination? Clin Cancer Res (2012) 18(4):920-2. doi:10.1158/1078-0432.CCR-11-3131

79. Minami D, Takigawa N, Takeda H, Takata M, Ochi N, Ichihara E, et al. Synergistic effect of olaparib with combination of cisplatin on PTEN-deficient lung cancer cells. Mol Cancer Res (2013) 11(2):140-8. doi:10.1158/1541-7786. MCR-12-0401

80. Cruz C, Teule A, Caminal JM, Blanco I, Piulats JM. Uveal melanoma and BRCA1/BRCA2 genes: a relationship that needs further investigation. J Clin Oncol (2011) 29(34):827-9. doi:10.1200/JCO.2011.37.8828

81. Jang S, Atkins MB. Treatment of BRAF mutant melanoma: the role of vemurafenib and other therapies. Clin Pharmacol Ther (2013) 95(1):24-31. doi:10.1038/clpt.2013.197

82. Matos AM, Francisco AP. Targets, structures, and recent approaches in malignant melanoma chemotherapy. ChemMedChem (2013) 8:1751-65. doi:10. $1002 / \mathrm{cmdc} .201300248$

83. Grimaldi AM, Cassidy PB, Leachmann S, Ascierto PA. Novel approaches in melanoma prevention and therapy. Cancer Treat Res (2014) 159:443-55. doi:10.1007/978-3-642-38007-5_25

84. Kim KB, Flaherty KT, Chapman PB, Sosman JA, Ribas A, McArthur GA, et al. Pattern and outcome of disease progression in phase I study of vemurafenib in patients with metastatic melanoma (MM). J Clin Oncol (2011) 29(Suppl):abstr8519.

85. Farolfi A, Ridolfi L, Guidoboni M, Nicoletti SV, Piciucchi S, Valmorri L, et al. Ipilimumab in advanced melanoma: reports of long-lasting responses. Melanoma Res (2012) 22(3):263-70. doi:10.1097/CMR.0b013e328353e65c

86. Korabiowska M, Konig F, Verheggen R, Schlott T, Cordon-Cardo C, Romeike $\mathrm{B}$, et al. Altered expression and new mutations in DNA mismatch repair genes MLH1 and MSH2 in melanoma brain metastases. Anticancer Res (2004) 24(2B):981-6.

87. Naumann SC, Roos WP, Jost E, Belohlavek C, Lennerz V, Schmidt CW, et al. Temozolomide- and fotemustine-induced apoptosis in human malignant melanoma cells: response related to MGMT, MMR, DSBs, and p53. Br J Cancer (2009) 100(2):322-33. doi:10.1038/sj.bjc.6604856

88. Toshimitsu H, Yoshimoto Y, Augustine CK, Padussis JC, Yoo JS, Angelica Selim M, et al. Inhibition of poly(ADP-ribose) polymerase enhances the effect of chemotherapy in an animal model of regional therapy for the treatment of advanced extremity malignant melanoma. Ann Surg Oncol (2010) 17(8):2247-54. doi:10.1038/sj.bjc.6604856
89. Bedikian AY, Papadopoulos NE, Kim KB, Hwu WJ, Homsi J, Glass MR, et al. A phase IB trial of intravenous INO-1001 plus oral temozolomide in subjects with unresectable stage-III or IV melanoma. Cancer Invest (2009) 27(7):756-63. doi:10.1080/07357900802709159

90. Plummer R, Jones C, Middleton M, Wilson R, Evans J, Olsen A, et al. First and final report of a phase II study of the poly(ADP-ribose) polymerase (PARP) inhibitor, AG014699, in combination with temozolomide (TMZ) in patients with metastatic malignant melanoma (MM). J Clin Oncol (2006) 24:8013. doi:10.1158/1078-0432.CCR-08-1223

91. Plummer R, Lorigan P, Steven N, Scott L, Middleton MR, Wilson RH, et al. A phase II study of the potent PARP inhibitor, rucaparib (PF-01367338, AG014699), with temozolomide in patients with metastatic melanoma demonstrating evidence of chemopotentiation. Cancer Chemother Pharmacol (2013) 71(5):1191-9. doi:10.1007/s00280-013-2113-1

92. Phase 2 Study of the Poly(ADP-Ribose) Polymerase Inhibitor E7016 in Combination With Temozolomide in Subjects With Wild Type BRAF Stage IV or Unresectable Stage III Melanoma (2012). Available from: www.clinicaltrials.gov

93. Study of Poly (ADP-Ribose) Polymerase (PARP) Inhibitor E7016 in Combination with Temozolomide in Subjects with Advanced Solid Tumors (2013). Available from: www.clinicaltrials.gov

94. Salama AK. Evolving pharmacotherapies for the treatment of metastatic melanoma. Clin Med Insights Oncol (2013) 7:137-49. doi:10.4137/CMO.S9565

95. Habbe N, Langer P, Sina-Frey M, Bartsch DK. Familial pancreatic cancer syndromes. Endocrinol Metab Clin North Am (2006) 35(2):417-30,xi. doi:10.1016/j.ecl.2006.02.016

96. Cancer risks in BRCA2 mutation carriers. The breast cancer linkage consortium. J Natl Cancer Inst (1999) 91(15):1310-6.

97. Leung K, Saif MW. BRCA-associated pancreatic cancer: the evolving management. JOP (2013) 14(2):149-51. doi:10.6092/1590-8577/1462

98. Drew Y, Mulligan EA, Vong WT, Thomas HD, Kahn S, Kyle S, et al. Therapeutic potential of poly(ADP-ribose) polymerase inhibitor AG014699 in human cancers with mutated or methylated BRCA1 or BRCA2. J Natl Cancer Inst (2011) 103(4):334-46. doi:10.1093/jnci/djq509

99. Kaufman B, Shapira-Frommer R, Schmutzler RK, Audeh MW, Friedlander M, Balmaña J, et al. Olaparib monotherapy in patients with advanced cancer and a germ-line BRCA1/2 mutation: an open-label phase II study. J Clin Oncol (2013) 31(Suppl):abstr11024.

100. Pishvaian M, Wang H, Zhuang T, He A, Hwang J, Hankin A, et al. A phase I/II study of ABT-888 in combination with 5-fluorouracil (5-FU) and oxaliplatin (Ox) in patients with metastatic pancreatic cancer (MPC). J Clin Oncol (2013) 30(Suppl 34):abstr147.

101. Edwards SM, Kote-Jarai Z, Meitz J, Hamoudi R, Hope Q, Osin P, et al. Two percent of men with early-onset prostate cancer harbor germline mutations in the BRCA2 gene. Am J Hum Genet (2003) 72(1):1-12. doi:10.1086/345310

102. Tryggvadottir L, Vidarsdottir L, Thorgeirsson T, Jonasson JG, Olafsdottir EJ, Olafsdottir GH, et al. Prostate cancer progression and survival in BRCA2 mutation carriers. J Natl Cancer Inst (2007) 99(12):929-35. doi:10.1093/jnci/djm005

103. Castro E, Goh C, Olmos D, Saunders E, Leongamornlert D, Tymrakiewicz $\mathrm{M}$, et al. Germline BRCA mutations are associated with higher risk of nodal involvement, distant metastasis, and poor survival outcomes in prostate cancer. J Clin Oncol (2013) 31(14):1748-57. doi:10.1200/JCO.2012.43.1882

104. Sandhu SK, Omlin A, Hylands L, Miranda S, Barber LJ, Riisnaes R, et al. Poly (ADP-ribose) polymerase (PARP) inhibitors for the treatment of advanced germline BRCA2 mutant prostate cancer. Ann Oncol (2013) 24(5):1416-8. doi:10.1093/annonc/mdt074

105. Schiewer MJ, Morey LM, Burd CJ, Liu Y, Merry DE, Ho SM, et al. Cyclin D1 repressor domain mediates proliferation and survival in prostate cancer. Oncogene (2009) 28(7):1016-27. doi:10.1038/onc.2008.446

106. Tan SH, Furusato B, Fang X, He F, Mohamed AA, Griner NB, et al. Evaluation of ERG responsive proteome in prostate cancer. Prostate (2013) 74(1):70-89. doi:10.1002/pros.22731

107. Tomlins SA, Rhodes DR, Perner S, Dhanasekaran SM, Mehra R, Sun XW, et al. Recurrent fusion of TMPRSS2 and ETS transcription factor genes in prostate cancer. Science (2005) 310(5748):644-8. doi:10.1126/science.1117679

108. Brenner JC, Ateeq B, Li Y, Yocum AK, Cao Q, Asangani IA, et al. Mechanistic rationale for inhibition of poly(ADP-ribose) polymerase in ETS gene fusionpositive prostate cancer. Cancer Cell (2011) 19(5):664-78. doi:10.1016/j.ccr. 2011.04 .010 
109. Chatterjee P, Choudhary GS, Sharma A, Singh K, Heston WD, Ciezki J, et al. PARP inhibition sensitizes to low dose-rate radiation TMPRSS2-ERG fusion gene-expressing and PTEN-deficient prostate cancer cells. PLoS One (2013) 8(4):e60408. doi:10.1371/journal.pone.0060408

110. Sandhu SK, Schelman WR, Wilding G, Moreno V, Baird RD, Miranda S, et al. The poly(ADP-ribose) polymerase inhibitor niraparib (MK4827) in BRCA mutation carriers and patients with sporadic cancer: a phase 1 dose-escalation trial. Lancet Oncol (2013) 14(9):882-92. doi:10.1016/S1470-2045(13)70240-7

111. TOPARP. A phase II trial of olaparib in patients with advanced castration resistant prostate cancer (2012). Available from: www.clinicaltrials.gov

112. Palma JP, Wang YC, Rodriguez LE, Montgomery D, Ellis PA, Bukofzer G, et al. ABT-888 confers broad in vivo activity in combination with temozolomide in diverse tumors. Clin Cancer Res (2009) 15(23):7277-90. doi:10.1158/10780432.CCR-09- 1245

113. Hussain M, Carducci MA, Slovin SF, Jeremy PC, Jiang Q, McKeegan EM, et al. Pilot study of veliparib (ABT-888) with temozolomide (TMZ) in patients (pts) with metastatic castration-resistant prostate cancer (mCRPC). J Clin Oncol (2012) 30(Suppl 5):abstr224.

114. Miquel C, Jacob S, Grandjouan S, Aime A, Viguier J, Sabourin JC, et al. Frequent alteration of DNA damage signalling and repair pathways in human colorectal cancers with microsatellite instability. Oncogene (2007) 26(40):5919-26. doi:10.1038/sj.onc.1210419

115. Vilar E, Bartnik CM, Stenzel SL, Raskin L, Ahn J, Moreno V, et al. MRE11 deficiency increases sensitivity to poly(ADP-ribose) polymerase inhibition in microsatellite unstable colorectal cancers. Cancer Res (2011) 71(7):2632-42. doi:10.1158/0008-5472.CAN-10-1120

116. Takahashi M, Koi M, Balaguer F, Boland CR, Goel A. MSH3 mediates sensitization of colorectal cancer cells to cisplatin, oxaliplatin, and a poly(ADP-ribose) polymerase inhibitor. J Biol Chem (2011) 286(14):12157-65. doi:10.1074/jbc. M110.198804

117. Thomas HD, Calabrese CR, Batey MA, Canan S, Hostomsky Z, Kyle S, et al. Preclinical selection of a novel poly(ADP-ribose) polymerase inhibitor for clinical trial. Mol Cancer Ther (2007) 6(3):945-56. doi:10.1158/1535-7163.MCT06-0552

118. Leichman LP, Cohen SJ, Hochster HS, Messersmith WA, Lenz H, Boman BM, et al. A phase II trial to assess the single-agent efficacy and safety of the PARP inhibitor olaparib $(\mathrm{O})$ in previously treated patients (pts) with metastatic, measurable colorectal cancer (mCRC) stratified by microsatellite status (MSs). Presented at 2010 Molecular Markers Meeting. Hollywood, FL (2012). Available from: http://meetinglibrary.asco.org/content/60883-101

119. Shelton JW, Waxweiler TV, Landry J, Gao H, Xu Y, Wang L, et al. In vitro and in vivo enhancement of chemoradiation using the oral parp inhibitor ABT-888 in colorectal cancer cells. Int J Radiat Oncol Biol Phys (2013) 86(3):469-76. doi:10.1016/j.ijrobp.2013.02.015

120. Pishvaian MJ, Slack R, Witkiewicz A, He AR, Hwang JJ, Hankin A, et al. A phase II study of the PARP inhibitor ABT-888 plus temozolomide in patients with heavily pretreated, metastatic colorectal cancer. J Clin Oncol (2011) 29(Suppl 15):abstr3502.

121. Lee MN, Tseng RC, Hsu HS, Chen JY, Tzao C, Ho WL, et al. Epigenetic inactivation of the chromosomal stability control genes BRCA1, BRCA2, and XRCC5 in non-small cell lung cancer. Clin Cancer Res (2007) 13(3):832-8. doi:10.1158/1078-0432.CCR-05-2694

122. Paul I, Savage KI, Blayney JK, Lamers E, Gately K, Kerr K, et al. PARP inhibition induces BAX/BAK-independent synthetic lethality of BRCA1-deficient nonsmall cell lung cancer. J Pathol (2011) 224(4):564-74. doi:10.1002/path.2925

123. Parp Inhibitor in Advanced Non-Small Cell Lung Cancer (PIN) (2013). Available from: www.clinicaltrials.gov

124. Wang D, Lippard SJ. Cellular processing of platinum anticancer drugs. Nat Rev Drug Discov (2005) 4(4):307-20. doi:10.1038/nrd1691

125. Cheng H, Zhang Z, Borczuk A, Powell CA, Balajee AS, Lieberman HB, et al. PARP inhibition selectively increases sensitivity to cisplatin in ERCC1low non-small cell lung cancer cells. Carcinogenesis (2013) 34(4):739-49. doi:10.1093/carcin/bgs393
126. Michels J, Vitale I, Senovilla L, Enot DP, Garcia P, Lissa D, et al. Synergistic interaction between cisplatin and PARP inhibitors in non-small cell lung cancer. Cell Cycle (2013) 12(6):877-83. doi:10.4161/cc.24034

127. Campelo RB, Felip E, Massuti B, Majem M, Carcereny E, Cardenal F, et al. Phase IB study of olaparib (AZD2281) plus gefitinib in EGFR-mutant patients (p) with advanced non-small-cell-lung cancer (NSCLC) (NCT 01513174/GECPGOAL). J Clin Oncol (2013) 31(Suppl):abstr2581.

128. Olaparib Dose Escalating Trial and Concurrent Radiotherapy With or Without Cisplatin in Locally Advanced NSCLC (2012). Available from: www. clinicaltrials.gov

129. Tomlins SA, Laxman B, Dhanasekaran SM, Helgeson BE, Cao X, Morris DS, et al. Distinct classes of chromosomal rearrangements create oncogenic ETS gene fusions in prostate cancer. Nature (2007) 448(7153):595-9. doi:10.1038/nature06024

130. Brenner JC, Feng FY, Han S, Patel S, Goyal SV, Bou-Maroun LM, et al. PARP-1 inhibition as a targeted strategy to treat Ewing's sarcoma. Cancer Res (2012) 72(7):1608-13. doi:10.1158/0008-5472.CAN-11-3648

131. Garnett MJ, Edelman EJ, Heidorn SJ, Greenman CD, Dastur A, Lau KW, et al. Systematic identification of genomic markers of drug sensitivity in cancer cells. Nature (2012) 483(7391):570-5. doi:10.1038/nature11005

132. Study of BMN 673, a PARP Inhibitor, in Patients with Advanced or Solid Tumors (2013). Available from: www.clinicaltrials.gov

133. Olaparib in Adults with Recurrent/Metastatic Ewing's Sarcoma (2012). Available from: www.clinicaltrials.gov

134. Kummar S, Kinders R, Gutierrez ME, Rubinstein L, Parchment RE, Phillips LR, et al. Phase 0 clinical trial of the poly (ADPribose)polymerase inhibitor ABT-888 in patients with advanced malignancies. J Clin Oncol (2009) 27(16):2705-11. doi:10.1200/JCO.2008.19.7681

135. Dhillon KK, Swisher EM, Taniguchi T. Secondary mutations of BRCA1/2 and drug resistance. Cancer Sci (2011) 102(4):663-9. doi:10.1111/j.1349-7006. 2010.01840

136. Norquist B, Wurz KA, Pennil CC, Garcia R, Gross J, Sakai W, et al. Secondary somatic mutations restoring BRCA1/2 predict chemotherapy resistance in hereditary ovarian carcinomas. J Clin Oncol (2011) 29(22):3008-15. doi:10.1200/JCO.2010.34.2980

137. Fojo T, Bates S. Mechanisms of resistance to PARP inhibitors - three and counting. Cancer Discov (2013) 3(1):20-3. doi:10.1158/2159-8290

138. Montoni A, Robu M, Pouliot E, Shah GM. Resistance to PARP-inhibitors in cancer therapy. Front Pharmacol (2013) 4:18. doi:10.3389/fphar.2013.00018

139. Ang JE, Gourley C, Powell B, High H, Shapira-Frommer R, Castonguay V, et al. Efficacy of chemotherapy in BRCA1/2 mutation carrier ovarian cancer in the setting of poly(ADP-ribose) polymerase inhibitor resistance: a multiinstitutional study. Clin Cancer Res (2013) 19(19):5485-93. doi:10.1158/10780432

Conflict of Interest Statement: The authors declare that the research was conducted in the absence of any commercial or financial relationships that could be construed as a potential conflict of interest.

Received: 07 November 2013; accepted: 18 February 2014; published online: 28 February 2014.

Citation: O'Sullivan CC, Moon DH, Kohn EC and Lee J-M (2014) Beyond breast and ovarian cancers: PARP inhibitors for BRCA mutation-associated and BRCA-like solid tumors. Front. Oncol. 4:42. doi: 10.3389/fonc.2014.00042

This article was submitted to Cancer Molecular Targets and Therapeutics, a section of the journal Frontiers in Oncology.

Copyright (C) 2014 O'Sullivan, Moon, Kohn and Lee. This is an open-access article distributed under the terms of the Creative Commons Attribution License (CC BY). The use, distribution or reproduction in other forums is permitted, provided the original author(s) or licensor are credited and that the original publication in this journal is cited, in accordance with accepted academic practice. No use, distribution or reproduction is permitted which does not comply with these terms. 